\title{
MEPAZINE (PACATAL), MEPERIDINE, AND \\ DIHYDROCODEINE (NADEINE) IN LABOUR
}

\section{E. PURKIS, M.B., B.S., F.F.A.R.C.s. ${ }^{1}$}

THE SEARCH for the ideal analgesic agent or combination for pain relief in labour has proceeded in recent years with the diligence of alchemists seeking to transmute lead into gold. While the borders of the problem have become more clearly defined $_{x}$ many workers feel that ideal analgesia is a goal which must be aimed at, but one which is unlikely to be achieved. All effective systemic analgesic agents are respiratory depressants, and adequate pain relief in the mother with these drugs can often only be achieved at the price of delayed respiration in the infant.

Conduction techniques of spinal and epidural, regional and local anaesthesia are not applicable in every labour, and can only be safely practised in centres with adequate facilities.

Prenatal instruction of the mother and positive efforts to secure a relaxed cooperative patient in labour can do much to reduce the dosage of systemic analgesics, but there will, be many occasions in many institutions where these drugs will be required to alleviate distress.

Recently, attention has been directed to the combination of reduced doses of analgesics with phenothiazine derivatives. These latter drugs have a powerful and distinctive central sedative action, and potentiate narcotic and hypnotic drugs, although they have no analgesic action of their own. Reduction in the dosage of analgesic required is thought to be reflected in a lower incidence of. infants requiring active resuscitation.

Chlorpromazine was reported by Savage (5) to produce marked calming and potentiation of analgesics; without depressing foetal respiration or adversely affecting the third stage of labour. Unfortunately, he also found marked prolongation of labour and an increased incidence of forceps delivery, indicating depression of uterine tone.

Promethazine has been reported by Carroll and his colleagues $(1,3)$ to produce a slight reduction in the length of labour, a definite reduction in meperidine dosage, and calm co-operative conditions in labour. The reduced dosage of meperidine resulted in undepressed infants, and an apparent reduction in pulmonary disorders of neonates occurred.

In a preliminary report on mepazine (Pacatal) by the author (6) similar calming effects' with no apparent depression of uterine contractions were noted in the mother, while the infants appeared active and showed no evidence of respiratory depression. Other side-effects of phenothiazine derivatives such as hypotension, vasodilation, and restlessness were minimal.

\footnotetext{
${ }^{1}$ Assistant Professor of Anaesthesia, Dalhousiej University, Nova Scotia; formerly Clinical Fellow, Royal Victoria Hospital, Montreal.
} 
The present investigation was undertaken to obtain a more accurate assessment of the effects of mepazine on labour, and upon the foetus, when used alone, or in combination with other analgesic drugs.

\section{AgEnTs}

Mepazine was used in combination with two analgesic agents. Meperidine, chosen as the systemic analgesic most commonly employed in obstetrics, was alternated with a newer analgesic, dihydrocodeine (Nadeine). Dihydrocodeine is a synthetic derivative of morphine elaborated in 1935 and recently reassessed by Beecher's group in Boston (2). They found that it was a potent analgesic in postoperative pain, though 12 per cent weaker than morphine, and had the advantage of minimal side-effects at optimum dose levels. The use of dihydrocodeine with scopolamine in obstetrics has been reported by Ruch and Ruch (4) and it was felt that this drug potentiated by mepazine would provide effective analgesia with minimal respiratory depression.

\section{Materlal}

Details were recorded from all public and semi-public patients admitted to the labour wards of the Royal Victoria Hospital, Montreal, between January 25 and July 29, 1958. Two-thirds of these patients could not understand English, onethird being French-speaking only, and the remaining third consisting of patients who could speak only Greek, Italian, German, Hungarian, Ukrainian, Jugoslavian, Finnish, or Chinese. These patients were, therefore, not accessible to verbal reassurance and explanation in the majority of instances.

\section{TABLE I}

Nemerical Distribution of All Cases Delitered BETWEEN JANUARY 25 AND JULY 29 ON MARDS UNDER OBSERTATION, WITH ANalysis OF CASEs Excluded from Series

\begin{tabular}{|c|c|c|c|}
\hline & Control & Trial & \\
\hline No drugs & 94 & 199 & \\
\hline Demerol only: & 102 & 47 & \\
\hline Pacatal only & - & 144 & \\
\hline Pacatal añd Demerol & - & 104 & \\
\hline $\begin{array}{l}\text { Pacatal and } \\
\text { dihydrocodeine }\end{array}$ & - & 101 & \\
\hline Dihydrocodeine alone & - & 14 & \\
\hline Other drugs & 14 & 35 & \\
\hline Total cases included & 210 & 644 & 854 \\
\hline Exclusions & & & \\
\hline Stillborn & 7 & 14 & \\
\hline $\begin{array}{l}\text { Prematures excluded } \\
\text { (less than } 28\end{array}$ & & & \\
\hline weeks) & 1 & 3 & \\
\hline Caesarean section & $\overline{5}$ & 23 & \\
\hline Born before & & & \\
\hline admission & 1 & 1 & \\
\hline Total cases excluded & 16 & 41 & 57 \\
\hline ALL CASES & & & 911 \\
\hline
\end{tabular}


It was decided to exclude those undergoing Caesarean section, those in whom labour resulted in a stillbirth, or the birth of a foetus of less than 28 weeks maturity, and those admitted to the labour ward after delivery.

The numerical distribution of the cases in the control and in the trial period, together with an analysis of exclusions is shown in Table $\mathrm{I}$.

\section{METHOD}

Proformae were prepared for recording the details of labour, the state of the foetus before and after delivery, and the timing and dosage of drugs given:

\section{Proforma For Recording LABDUR DetaILS}

Infant

Foetal distress before delivery:

Tachycardia/Bradycardia

Irregularity, Meconium

Cord around neck Yes/No

Condition at birth: Tone: Good/Fair

$$
\text { Poor/Absent }
$$

Cy'anosis: Slight:

Moderate/Marked

Time from delivery to rhythmic spontaneous respiration........... secs.

Resuscitation: O.2 Bag \& Mask; Art, Respn. Resp. Stim. Narcotic Ant.

Heart rate at $1 \mathrm{~min}$.: Under $100: 100-160$ Over 160

Respiration at 1 min.: Reg. \& deep Reg \& shallow Irregular Gasping None

Ref. Anaesthesia and Anulgesia:

Co-operation of patient: Grood. Lair poor Pacatal: No. of doses

Demerol: No. of doses

Dihydrocodeine: No. of doses

Barbiturate: No. of doses

Trilene analgesia for......... mins.

Gen. Anaesthesia: Agents:
Addressograph stamp
Gravida:

Due Date:

Admitted:......am; ${ }^{\prime}$ pm

Date

1st Stage began...... am, pm, on ..... 2nd Stage began...... am; $[\mathrm{m}$, on ..... Delivered:..........am; pm, on ..... 3rd Stage complete.... am . pm, on ......

Position:

Type of Delivery: Spont. Forceps Posterior; rotation Breech Extraction

Del of Placenta: Spont., Fundal P.: Man. Rem.

Placenta: Normal Infarcted, Old retroplacental clot

Blood Loss: cc.s

Total dose Time of last dose Total dose Time of last dose Total dose Time of last dose Total dose Time of last dose $\mathrm{N}_{2} \mathrm{O}, \mathrm{O}_{2}$ analgesia for . . . . . . . mins. Time to delivery..............mins. Total duration...............mins.

The initial observations on these proformae were recorded by the anaesthetists, where they were present at cases receiving inhalation analgesia or anaesthesia for delivery. Where an anaesthetist was not present, information was extracted by the investigator from similar records maintained by the obstetric staff. 
The investigator completed the proforma in all cases, using the above sources, the patients' hospital records, and the replies to questions directed to the patients within 48 hours of delivery on their attitude to the labour and the analgesia received. Where possible these questions were posed in the patients' own language with or without the aid of an interpreter.

\section{Post-Delivery Questionnaire}

Completed within 48 hours of the delivery.

(1) Primigravidae: Was labour better than expected? worse than expected? as expected?

(2) Multigravidae: Was labour better than previous labours? worse than previous labours? the same as previous labours?

(3) At its worst was the pain experienced mild? severe? unbearable?

(4) "Was the relief of pain by injections good?

fair? poor? nil?

(5) While you were awake was the relief of pain by mask good?

fair? poor? nil?

(6) Do you remember admission, rupture of membranes, enema, being transferred to delivery room, birth of the baby, delivery of the afterbirth, returning to this ward?

The investigation was divided into three periods, each designed to end when 100 case records of the main drug concerned were obtained. The periods were:

(a) Control period, January 25-March 19, during which the current practice was observed, with no attempt to influence the type, time or dosage of drugs given.

(b) Period where the analgesic was limited to meperidine and instructions were given for all patients to receive mepazine by mouth in a dosage of 0.75 $\mathrm{mg}$. $/ \mathrm{kg}$. every $4 \mathrm{hrs}$. from the time of admission onwards, provided that they were experiencing regular labour pains.

(c) Period where the analgesic was limited to dihydrocodeine and instructions for giving mepazine continued as in $(b)$ above.

In both groups $(b)$ and $(c)$ the timing and dose of the analgesic drug was left entirely to the discretion of the obstetric staff, apart from an initial suggestion that some reduction in dosage might be achieved without loss of analgesia.

Group $(b)$ and $(c)$ became intermingled in random fashion by the substitution of dihydrocodeine for meperidine in certain delivery rooms without the knowledge of the investigator or the obstetric staff, at a point halfway through the group $(b)$ period, so that the two groups ran side by side for a short time. When this became apparent, dihydrocodeine was prescribed until group $(c)$ was complete, and the trial ended by completion of the last third of group (b). 


\section{Results}

For comparison, the records may be divided into eight groups, seven according to the drugs received within 12 hours of delivery, and a control group consisting of the patients in the control period. These received no drugs, meperidine alone, or other drug combinations. The drug groups are: no drugs, meperidine alone, meperidine with mepazine, mepazine alone, dihydrocodeine with mepazine, dihydrocodeine alone, and other drugs. The:e other drugs were mainly barbiturates given for sleep in what was thought to be early labour, or for sedation in toxaemia, but on occasion morphine, heroin, alphaprodine, chlorpromazine, or narcotic antagonists were given before delivery.

The numerical distribution of these groups divided according to parity is shown in Table II. The small numbers in the case of the dihydrocodeine alone

TABLE II

Numerical Distribution of Ciases by Grovps ACCORDing to Drugs Received

\begin{tabular}{|c|c|c|c|}
\hline Group & Primigravidae & Multigravi & dae \\
\hline \multicolumn{4}{|l|}{ No drugs } \\
\hline Controls & 16 & 79 & \\
\hline Trials & 30 & 168 & \\
\hline Total & 46 & 247 & \\
\hline \multicolumn{4}{|l|}{ Demerol only } \\
\hline Controls & 56 & $4 i$ & \\
\hline Trial & 24 & 22 & \\
\hline Total & 30 & 69 & \\
\hline Demerol and Pacatal & 57 & 47 & \\
\hline Pacatal only & 42 & 102 & \\
\hline Dihydrocodeine only & 8 & 6 & \\
\hline Dihydrocodeine and Pacatal & 55 & 46 & \\
\hline \multicolumn{4}{|l|}{$\begin{array}{l}\text { Other drugs } \\
\text { Otull }\end{array}$} \\
\hline Controls & & $\bar{i}$ & \\
\hline Trial & & 22 & \\
\hline Total & 20 & 29 & \\
\hline Exclusions & 21 & 36 & \\
\hline Total included & 308 & 546 & 854 \\
\hline Total excluded & & & $5 i$ \\
\hline GRANT) TOTAL & & & 911 \\
\hline
\end{tabular}

group result from the decision to abandon the use of this drug alone due to unsatisfactory analgesia.

\section{EFFECTS ON THE INFANT}

The main assessment of drug effects in the infant is based on a comparison of the time to regular rhythmic respiration as distinct from time of the first breath or cry. While this is a more difficult end point to assess, it offers a more reliable measure of the state of depression since drug-depressed infants may be born well oxygenated and with good tone, and may grimace or cry, or make a few gasping respirations before relapsing into an apnoea which tends to be prolonged by the ensuing anoxia. These observations were recorded by thirteen anaesthetists, and it is felt that any individual bias in determining. the end point would be compensated by an opposite bias in other observers. 
I. E. PURKIS: MEPAZINE, MEPERIDINE, AND DIHYDDOCODEINE

There was a significant difference $(P<.05-P<.001)$ in four out of eight groups between infants of primigravidae and infants of multigravidae, so that these groups have been compared separately and are shown in Table III.

TABLE III

Comparison of Time to Regular Respiration in Infants According to Drug Group and Parity of Mother

\begin{tabular}{lcc}
\hline Group & $\begin{array}{c}\text { Infants born of } \\
\text { inrinigravidae } \\
\text { (mean time ir sec.) }\end{array}$ & $\begin{array}{c}\text { Infants born of } \\
\text { multigravidae } \\
\text { (mean time in sec.) }\end{array}$ \\
\hline Controls & 88.6 & 34.2 \\
No drugs & 65.6 & 48.0 \\
Demlerol only & 69.8 & 38.0 \\
Demerol and Pacatal & 75.3 & 46.0 \\
Pacatal only & 44.7 & 30.4 \\
Dihydrocodeine only' & 133.0 & 25.0 \\
Dihydrocodeine and Pacatal & 70.3 & 55.2 \\
Other drugs & 109.3 & $\mathbf{7 5 . 9}$ \\
\hline
\end{tabular}

*Significantly faster than control $(P .<.05)$

As can be seen, there is little evidence of drug depression in any group except the dihydrocodeine alone and the other drug groups, and the numbers here are too small to be significant.

However, the respiration time in the mepazine group is faster than control $(P<.05$ in primigravidae $)$ and faster than dihydrocodeine $(P<.02$ in primigravidae) and closely approaches significance when compared with those receiving no drugs. This suggests that of itself mepazine tends to stimulate the earlier onset of foetal respiration.

Among other factors which may affect the regular respiration time of infants are signs of foetal distress before delivery, the percentage of infants showing delay in reaching regular respiration beyond $2 \mathrm{~min}$. and the incidence of infants requiring active resuscitation. These are compared in Table IV.

TABLE IV

Comparison of the incidence of Foetal Distress, Delayed Respiration, and Active Resuscitation in Drug Groufs, by Parity

\begin{tabular}{|c|c|c|c|c|c|c|}
\hline \multirow[b]{2}{*}{ Group } & \multicolumn{2}{|c|}{$\begin{array}{l}\text { Infants showing } \\
\text { distress }(\%)\end{array}$} & \multicolumn{2}{|c|}{$\begin{array}{c}\text { Inlants breathing } \\
\text { later than } 2 \text { min. }(\%)^{*}\end{array}$} & \multicolumn{2}{|c|}{$\begin{array}{l}\text { Infants requiring } \\
\text { resuscitation }(\%)\end{array}$} \\
\hline & $\begin{array}{l}\text { Primi- } \\
\text { gravidae }\end{array}$ & $\begin{array}{l}\text { Multi- } \\
\text { gravidae }\end{array}$ & $\begin{array}{c}\text { Primi- } \\
\text { gravidae }\end{array}$ & $\begin{array}{l}\text { Multi- } \\
\text { gravidae }\end{array}$ & $\begin{array}{l}\text { Primi- } \\
\text { gravidae }\end{array}$ & $\begin{array}{c}\text { Multi- } \\
\text { gravidae }\end{array}$ \\
\hline Control & 20.0 & 6.8 & 16.3 & 4.5 & 12.5 & 2.3 \\
\hline No drug & 13.0 & 11.3 & 19.6 & 5.3 & 10.9 & 2.8 \\
\hline Demerol only & 23.7 & 10.1 & 13.8 & 8.7 & 11.3 & 5.8 \\
\hline Demerol and Pacatal & 15.8 & 14.9 & 24.6 & 6.4 & 17.5 & 6.4 \\
\hline Pacatal only & 30.9 & 12.7 & 16.7 & 2.9 & 9.5 & 1.0 \\
\hline Dihydrocodeine only & 0.0 & 0.0 & 37.5 & 0.0 & 50.0 & 0.0 \\
\hline Dihydrocodeine and Pacatal & 14.5 & 13.0 & 18.0 & 13.9 & 12.7 & 15.2 \\
\hline Other drugs & 20.0 & 6.9 & 25.0 & 10.3 & 15.0 & 6.9 \\
\hline
\end{tabular}

"Breathing regularly and rhythmically. 
Foetal distress was noted most frequently in primigravidae receiving mepazine only, and next most frequently in those receiving meperidine only, while in multigravidae the highest incidence occurs in the group receiving mepazine with meperidine or with dihydrocodeine. However, the variations either side of control are such that these could have arisen by coincidence, and cannot be consistently ascribed to any one drug or combination. Moreover, the correlation between signs of foetal distress and the occurrence of delayed respiration was very poor, only 5 per cent of all distressed infants showing delay. The most reliable indication of distress was bradycardict, alcne or with irregularity, or a combination of any three signs of foetal distress.

Surprisingly, the correlation between prematurity or post-maturity, judged from the calculated date of delivery, and delayed respiration was also poor: 7.54 per cent of infants born to the 854 mothers were born before the thirty-sixth week, and 5.8 per cent after the forty-fourth week. Of these infants, only 10.7 per cent of prematures and 16 per cent of post-matures showed any delay in attaining regular respiration.

Many infants showing delay in the onset of regular respiration were breathing adequately and required no resuscitation. Conversely, many infants thought to require resuscitation were rapidly revived and showed no delay in achieving regular respiration. All infants were suctioned with mucus catheters and placed in a warm 40 per cent oxygen atmosphere. Active resuscitation consisted of giving 100 per cent oxygen to a breathing infant, using a bag and mask. Very rarely, endotracheal intubation was performed to enable the airway to be aspirated more thoroughly.

Primigravidae receiving meperidine with mepazine showed the highest incidence of delayed respiration and their infants required resuscitation more frequently. Since this group had the highest incidence of abnormal positions of the foetus at the onset of labour (that is, any position other than left or right occipito anterior), this finding is not unexpected, and cannot be attributed to the particular drug combination.

\section{Drug Dosage and Timing (See Table $\mathrm{X}$ )}

There was a significant difference in dosage in all groups receiving narcotics between multigravidae and primigravidae, varying between $P<.05$ to $P<.001$. There is a highly significant difference $(P<.001)$ between the dosage of meperidine alone (mean: 151.2 in primigravidae, $105.4 \mathrm{mg}$. in multigravidae) and the dosage of meperidine when combined with mepazine (mean: 80.0 in primigravidae, 75.5 in multigravidae).

Dihydrocodeine when given alone in doses of $30-50 \mathrm{mg}$., resulted in a degree of analgesia which was obviously inadequate in the judgment of the obstetric and nursing staffs. Over 50 per cent of the patients also stated that they received poor or no relief of pain from dihydrocodeine alone. Indeed, many denied they had received an analgesic, being under the impression that the injection had been given with the object of accelerating labour. Dihydrocodeine possesses a central excitatory activity similar to that shown by codeine, and might well affect uterine 
activity in this way. There is evidence in comparing the length of labour between groups that this impression is correct.

Since the main criterion for comparisons between the groups is that, objectively, equivalent pain relief should have been attained in each group, the differences between those receiving dihydrocodeine alone and those receiving dihydrocodeine and mepazine are not considered comparable, especially in view of the small numbers in the former group. In the dihydrocodeine with mepazine group, satisfactory analgesia was obtained with a 50-75 mg. dose, followed in the case of the smaller initial dose, by a second dose of $30 \mathrm{mg}$. in 2 hours. However, these higher dosage levels were followed by an increased incidence of delayed respiration in the infants, and a higher percentage of infants requiring active resuscitation, especially noticeable in infants of multigravidae.

The mean dosage of narcotic in the group receiving dihydrocodeine alone was $56 \mathrm{mg}$. for primigravidae and $38.3 \mathrm{mg}$. for multigravidae, in contrast to the group receiving dihydrocodeine with mepazine, where the mean dosage was $75 \mathrm{mg}$. for primigravidae, and 52.9 for multigravidae.

There was no significant difference in the timing of the last dose of narcotic given to groups receiving narcotic alone as compared to groups receiving narcotic with mepazine, but the interval between the last dose and delivery was longer in the case of primigravidae ( $3.1-4.6$ hours) than of multigravidae (2.1-2.9 hours).

\section{EFFECTS ON THE MOTHER}

Clinical impressions of the obstetric staff and nursing staff were very favourable, and most remarked spontaneously that the labour wards had become quieter and more orderly. Patients rested well between pains and apprehension and fear were minimal in a group where the majority could not be reassured because of language difficulties.

The length of labour was recorded from the onset of regular rhythmic pains to the completion of the delivery of the placenta. In some cases, contractions, after being regular, became irregular and in some labour was suspended, sometimes for as long as 48 hours. Nevertheless, since the labour: process had started, onset of labour was accepted as defined above. Thus the mean labour times, given in Table $V$, tend to be a little longer in each group than those reported from other institutions.

Considering primigravidae, there was no significant difference in length of labour between those receiving no drugs, those receiving mepazine alone, and those receiving dihydrocodeine alone. Moreover, those receiving mepazine alone showed significantly shorter labour times than those receiving meperidine alone, meperidine with mepazine, dihydrocodeine with mepazine, and those in the control group. While the small numbers make it unwise to draw conclusions in the dihydrocodeine alone group, mepazine alone is shown to have a beneficial effect in shortening labour.

In the multigravidae, however, there are no significant differences except in the group receiving meperidine and mepazine alone, where labour is significantly slower than control. 
TABLE $V$

COMPakison of Mean Labour Times (in hours)

\begin{tabular}{|c|c|c|c|c|c|c|c|c|}
\hline \multirow[b]{2}{*}{ Group } & \multicolumn{4}{|c|}{ Primigravidae } & \multicolumn{4}{|c|}{ Multigravidae } \\
\hline & $\begin{array}{l}\text { First } \\
\text { stage }\end{array}$ & $\begin{array}{l}\text { Second } \\
\text { stage }\end{array}$ & $\begin{array}{l}\text { Third } \\
\text { stage }\end{array}$ & Total & $\begin{array}{l}\text { First } \\
\text { stage }\end{array}$ & $\begin{array}{l}\text { Second } \\
\text { stage }\end{array}$ & $\begin{array}{l}\text { Third } \\
\text { stage }\end{array}$ & Total \\
\hline Controls & 23.81 & 0.85 & 0.21 & 24.95 & 10.42 & 0.43 & 0.18 & 11.28 \\
\hline No drugs & 10.8 & 0.77 & 0.14 & 11.8 & 9.04 & 0.43 & 0.16 & 9.6 \\
\hline Demerol only & 21.52 & 0.92 & 0.19 & 2263 & 11.6 & 0.37 & 0.16 & 12.7 \\
\hline Demerol and Pacatal & 19.5 & 1.1 & 0.22 & 20.46 & 14.95 & 0.63 & 0.18 & $15.76 \dagger$ \\
\hline Pacatal only & 13.52 & 1.18 & 0.18 & $15.12^{*}$ & 10.99 & 0.52 & 0.17 & 11.69 \\
\hline Dihydrocodeine only & 17.15 & 0.59 & 0.2 & 17.94 & 11.55 & 0.32 & 0.17 & 12.03 \\
\hline $\begin{array}{l}\text { Dihydrocodeine and } \\
\text { Pacatal }\end{array}$ & & & & & & & & \\
\hline $\begin{array}{l}\text { Pacatal } \\
\text { Other drugs }\end{array}$ & 19.29 & 1.03 & 0.18 & 20.24 & 12.65 & 0.43 & 0.16 & 13.23 \\
\hline Other drugs & 27.85 & 1.13 & 0.13 & 29.07 & 15.4 & 0.46 & 0.18 & 16.03 \\
\hline
\end{tabular}

* Difference between Pacatal only group and groups receiving Demerol alone, Pacatal with Demerol, and Pacatal with dihydrocodeine significant at $P<.02$ level. Difference between Pacatal and control groups significant at $P<.01$ level.

†Significantly slower than control: $P<.01$.

In the individual stages, similar differences are present in the first stage, and the third stages are of similar length in all groups, but the second stage in groups receiving mepazine is slightly longer than other groups, though the difference is not significant.

Co-operation in the second stage of labour is shown in Table VI. Primigravidae reçeiving mepazine alone co-operated better than any other group, while those receiving meperidine alone or in combination with mepazine were similar to controls. Those receiving no drugs, and those receiving meperidine and mepazine showed the highest percentage of poor results, but once again, the high incidence of abnormal positions in this latter group should be borne in mind.

TABLE I'I

Co-operation of Patients in the Second Stage of Labour by Drug Group and Parity (\%)

\begin{tabular}{|c|c|c|c|c|c|c|c|c|}
\hline \multirow[b]{2}{*}{ Group } & \multicolumn{4}{|c|}{ Primigravidae } & \multicolumn{4}{|c|}{ Multigrayidae } \\
\hline & Good & Fair & Poor & $\begin{array}{l}\text { Not re- } \\
\text { corded }\end{array}$ & Good & Fair & Poor & $\begin{array}{l}\text { Not re } \\
\text { corded }\end{array}$ \\
\hline Control & 53.7. & 17.5 & 6.3 & 22.5 & 38.3 & 12.8 & 5.3 & +3.6 \\
\hline No drugs & 37.0 & 6.5 & 15.2 & 41.3 & 38.1 & 11.3 & 4.0 & 46.6 \\
\hline Demerol alone & 55.0 & 17.5 & 5.0 & 22.5 & 49.4 & 13.0 & 5.8 & 31.8 \\
\hline Demerol and Pacatal & 50.9 & 19.3 & 17.5 & 12.3 & 32.0 & 27.7 & 2.1 & 38.2 \\
\hline Pacatal alone & 619 & 14.3 & 2.4 & 21.4 & 50.0 & 15.7 & 8.8 & 25.5 \\
\hline Dihydrocodeine alone & 375 & 12.5 & 0.0 & 50.0 & 10.3 & 0.0 & 0.10 & 89.7 \\
\hline $\begin{array}{l}\text { Dihydrocodeine and } \\
\text { Racatal }\end{array}$ & & & & & & & & \\
\hline $\begin{array}{l}\text { Pacatal } \\
\text { Other drugs }\end{array}$ & $\begin{array}{l}509 \\
45.0\end{array}$ & $\begin{array}{l}18.2 \\
15.0\end{array}$ & $\begin{array}{l}3.6 \\
5.0\end{array}$ & $\begin{array}{l}21.3 \\
35.0\end{array}$ & $\begin{array}{l}4 b .6 \\
24.1\end{array}$ & $\begin{array}{l}23.9 \\
17.2\end{array}$ & $\begin{array}{l}4.8 \\
3.5\end{array}$ & 56.7 \\
\hline
\end{tabular}

In multigravidae the results are similar in all groups if it is assumed that the non-recorded results would have occurred in the same ratio as the recorded results. Once again, there is a marked increase in the incidence of fair and poor co-operation, in the group with many abnormatiabours. 
The incidence and type of anaesthesia are shown in Table VII. Nitrous oxideoxygen-trichlorethylene was the general anaesthetic most frequently employed, unconsciousness supervening at or a few minutes before crowning of the foetal head. Pudendal block was the most common type of local anaesthesia, though saddle block spinal and epidural were used on occasion.

TABLE VII

Nature of Anaesthesia Given for Delivery in Each Group, by Parity (\%)

\begin{tabular}{|c|c|c|c|c|c|c|}
\hline \multirow[b]{2}{*}{ Group } & \multicolumn{3}{|c|}{ Primigravidae } & \multicolumn{3}{|c|}{ Multigravidae } \\
\hline & General & $\begin{array}{l}\text { Local or } \\
\text { regional }\end{array}$ & None & General & $\begin{array}{l}\text { Local or } \\
\text { regional }\end{array}$ & None \\
\hline Control & 82.5 & 3.75 & 13.75 & 60.9 & 1.5 & 37.6 \\
\hline No drug & 78.25 & 13.0 & 8.75 & 57.5 & 3.6 & 38.9 \\
\hline Demerol alone & 81.3 & 7.5 & 11.2 & 65.2 & 1.4 & 33.4 \\
\hline Demerol and Pacatal & 82.5 & 6.3 & 6.2 & 68.1 & 6.4 & 25.5 \\
\hline Pacatal alone & 73.8 & 7.2 & 19.0 & 60.8 & 2.0 & 37.2 \\
\hline Dihydrocodeine alone & 75.0 & 12.25 & 12.25 & 50.0 & 16.6 & 33.4 \\
\hline Dihydrocodeine and Pacatal & 72.7 & 7.3 & 20.0 & 69.6 & 4.3 & 26.1 \\
\hline Other drugs & 70.0 & 10.0 & 20.0 & 27.6 & 0.0 & 7.24 \\
\hline
\end{tabular}

The records of blood lost are based on estimates given by the obstetric staff, and there is no significant difference between the groups or between primigravidae and multigravidae. The incidence of post partum haemorrhage (blood loss over $500 \mathrm{cc}$.) was higher in primigravidae than in multigravidae in all groups and is shown in Table VIII. There was a higher incidence in groups receiving narcotics alone, than in the groups receiving mepazine alone or in combination with a narcotic.

TABLE VIII

Percentage Incidence of Forceps Delivery and Post Partum Haemorrhage by Drug Group and Parity

\begin{tabular}{|c|c|c|c|c|}
\hline \multirow[b]{2}{*}{ Group } & \multicolumn{2}{|c|}{ Forceps delivery } & \multicolumn{2}{|c|}{ Post partum haemorrhage } \\
\hline & Primigravidae & : Multigravidae & Primigravidae & Multignavidae \\
\hline Control & 33.8 & 3.0 & 13.8 & +5 \\
\hline No drugs & 26.0 & 4.1 & 6.5 & 3.2 \\
\hline Demerol alone & 38.8 & 5.8 & 10.0 & 1.4 \\
\hline Demerol and Pacatal & 50.9 & 17.0 & 8.7 & 64 \\
\hline $\begin{array}{l}\text { Pacatal alone } \\
\text { Pat }\end{array}$ & 38.0 & 7.8 & 7.1 & 5.9 \\
\hline Dihydrocodeine alone & 50.0 & 0.0 & 12.5 & 0.0 \\
\hline Dihydrocodeine and Pacatal & 49.1 & 13.0 & 7.3 & 2.2 \\
\hline Other drugs & 41.4 & 3.5 & 20.0 & 6.9 \\
\hline
\end{tabular}

Consideration of the forceps rate shows the combination of mepazine with narcotics, or mepazine alone, to be associated with an increased incidence of forceps delivery in both primigravidae and multigravidae.

In assessing analgesia, the difficulties of evaluating replies from patients are recognized since their answers may be modified by the psychological elation or 
depression phases of the puerperium. However, leading questions were avoided by putting the question in the form of a choice between three alternatives, with no attempt to guide the patient to a particular reply. The replies were assigned unit values, being lowest for the favourable and highest for the unfavourable alternative, and on totalling the values, a scors is arrived at for each patient which is taken as a measure of the discomfort experienced. These scores are compared in Table IX.

TABLE $1 X$

Comparison of Analgesia Scipres Obtained from RESPONSES TO QUESTIONNAIRE

\begin{tabular}{|c|c|c|}
\hline Group & $\begin{array}{l}\text { Prinigravidae } \\
\text { (mean score) }\end{array}$ & $\begin{array}{l}\text { Multigravidae } \\
\text { (mean score)" }\end{array}$ \\
\hline Controls & 3.4 & 2.8 \\
\hline No drugs & 2.0 & 2.0 \\
\hline Demerol only & 3.7 & 4.0 \\
\hline Demerol and Pacatal & 4.4 & 5.3 \\
\hline Pacatal only & 24 & 2.3 \\
\hline Dihydrocodeine only & 57 & 44 \\
\hline Dihydrocodeine and Pacatal & 4.3 & 4.6 \\
\hline Other drugs & 3.24 & 3.14 \\
\hline
\end{tabular}

Those who received no analgesic could not, of course, score on this account, but if they experienced severe or unbearable pain because an analgesic was judged not necessary, their score would rise On the other hand, those obtaining good relief from air analgesic would not add to their score. It will be seen that those who received mepazine with meperidine or dihydrocodeine, or dihydrocodeine alone, suffered more discomfort than those receiving meperidine only. On the other hand, those who received mepazine alone suffered less discomfort than those who received meperidine.

TABLE $\mathbb{N}$

Mean Dosage and Time of Administration of Drugs by Groups

\begin{tabular}{|c|c|c|c|c|}
\hline \multirow[b]{2}{*}{ Group } & \multicolumn{2}{|c|}{ Mean drug dose (mg.) } & \multicolumn{2}{|c|}{ Mean time of last dose (hrs.) } \\
\hline & Primigravidae & Multigravidae & Primigravidae & Multigravidae \\
\hline Demerol in controls & 151.2 & $105 t$ & 3.7 & 2.7 \\
\hline $\begin{array}{l}\text { Demerol in Demerol only group } \\
\text { Demerol in Pacatal-Demerol }\end{array}$ & 139.0 & 1026 & 3.5 & 2.4 \\
\hline $\begin{array}{l}\text { Demerol in Pacatal-Demerol } \\
\text { group }\end{array}$ & 80.0 & 75.5 & 4.6 & 2.9 \\
\hline $\begin{array}{l}\text { Dihydrocodeine in dihydrocodeine } \\
\text { only group }\end{array}$ & 56.0 & 383 & 3.1 & 2.1 \\
\hline $\begin{array}{l}\text { Dihydrocodeine in dihydrocodeine- } \\
\text { Pacatal group }\end{array}$ & 750 & 529 & 3.8 & 23 \\
\hline Pacatal in Pacatal only group & 182.0 & 167.3 & 3.7 & 2.5 \\
\hline $\begin{array}{l}\text { Pacatal in Pacatal-Demerol } \\
\text { group }\end{array}$ & 267.0 & 229.0 & 3.6 & 3.4 \\
\hline $\begin{array}{l}\text { Pacatal in Pacatal- } \\
\text { dihydrocodeine group }\end{array}$ & 259.0 & 179.9 & 3.5 & 3.1 \\
\hline
\end{tabular}




\section{Conclusions}

The many factors which interact in any individual labour make the assessment of any drug effects very difficult, and no drugs are more difficult to assess than analgesics or analgesic combinations. However, in reviewing the material presented, the following conclusions seem justified.

By itself, mepazine has no influence on the length of labour in primigravidae or multigravidae and tends to stimulate the earlier onset of respiration in their infants. It will also give satisfactory sedation and relief of apprehension in a proportion of patients who would otherwise be given meperidine for this purpose. It increases the incidence of forceps delivery.

In combination with meperidine, there is potentiation of all the effects of the narcotic, and a marked reduction in dosage results. Because of this potentiation, the tendency of meperidine to depress foetal respiration is present almost to the same degree as with the higher dosage. Again, meperidine tends to lengthen labour through a reduction in uterine tone, and this effect is potentiated by mepazine, so that labour tends to be lengthened to almost the same degree as with the higher dose of meperidine. However, 'this effect is less noticeable in. primigravidae than in multigravidae, probably because labour is lengthened by apprehension and poor relaxation, and these are more common in primignavidae than multigravidae.

Although to the observer, the combination of meperidine and mepazine appears to produce better analgesia than meperidine alone; in the early puerperium, patients state that they suffered more discomfort with the combination.

Mepazine had no adverse effects on the third stage of labour, and no cases of liver dysfunction or depression of bone marrow occurred in patients receiving the drug.

Dihydrocodeine proved to be an inadequate analgesic in labour in $30-50 \mathrm{mg}$. doses, and attempts to increase the dose only resulted in increased respiratory depression in infants, with little increasel in analgesia. Combined with mepazine in 30-75 mg. doses, analgesia was comparable to that attained with meperidine and mepazine, and while labour was shorter, there was an increased incidence of delayed respiration in infants.

\section{SUMMARY}

A controlled trial of mepazine (Pacatal) alone and in combination with meperidine (Demerol) or dihydrocodeine '(Nadeine) in a series of 854 obstetrical patients is reported.

Mepazine alone stimulates the earlier onset of respiration in infants, does not lengthen labour and has no adverse effects on the third stage of labour. However, alone or in combination with a narcotic, mepazine increases the incidence of forceps delivery.

In combination with meperidine, satisfactory sedation and co-operation were obtained during labour, and a marked reduction in meperidine dosage resulted. In primigravidae, labour was shortened. The combination produced no greater respiratory depression in infants than did meperidine alone. 
Dihydrocodeine given alone in $30-50 \mathrm{mg}$. doses was an unsatisfactory analgesic in labour. Combined with mepazine, satisfactory sedation and co-operation were produced with $30-75 \mathrm{mg}$. doses, but at the price of increased respiratory depression in infants.

\section{RÉSUMÉ}

Voici le résultat de l'essai contrôlé de la mepazine (Pacatal) seule et en association avec la mépéridine (Demerol) ou la dihydrocodeine (Nadeine) chez 854 cas d'obstétrique.

Si elle est employée seule, la mepazine stimule la spontanéité respiratoire des enfants, elle ne prolonge pas le travail et elle n'a pas d'effets contraires sur le troisième stage du travail. Toutefois, qu'elle soit employée seule ou en association avec un narcotique, la mepazine augmente la fréquence des prises de forceps.

En l'associant à la mépéridine, nous avons obtenu durant le travail une sédation et une coopération satisfaisante et, de ce fail, les doses de meperidine ont été fortement diminuées. Chez les primipares, le travail a été plus court. Chez les enfants, la dépression respiratoire n'a pas été plus marquée avec l'association qu'avec la mépéridine seule.

La dihydrocodeine, employée seule, à la dose de 30-50 mg. au cours dlu travail, ne s'est pas avérée un analgésique satisfaisant. Associée à la mépazine à la dose de 30-75 mg., elle a donné une sédation et une coopération satisfaisantes, mais au prix d'une dépression respiratoire plus marquée chez les enfants.

\section{ACKNOWLEDGMENTS}

I should like to thank Dr. A. B. Noble, Dr. G. B. Maughan, Miss M. Fraser, and the anaesthetric and obstetric and nursing staffs, whose interest and co.operation proved invaluable. Warner-Chilcott Laboratories provided the Pacatal used in this series and gave valuable assistance in the preparation of records for analysis. Nadeau Laboratories provided generous supplies of Nadeine.

\section{REFERENCES}

1. Carroll, J. J., \& Hudson, P. IV. Canad. Anaesth. Soc. J. 2: 340 (1955).

2. Gravenstein, J. S.; Sinith, G. M.; Sphire, R. D.; Isaacs, J. P.; \& Beecher, H. K. New Eng. J. Med. 254: 87\% (1956).

3. Hobss, F. S., \& Canroll, J. J. Canad. M.A.J. 7 9: 822 (1958).

4. Ruch, W. A., \& Ruch, R. M. Am. J. Obst. \& Gynec. 74: 1125 (1957)

5. Savage, D. Brit. J. Anaesth. 27: 346 (1955).

6. Putuks, I. E. Canad. M.A.J. i8: 24.5 ( 1958 ). 